\title{
Factors Associated with Maternal Deaths in District and Upazila Hospitals of Bangladesh
}

\author{
ABDUL HALIM ${ }^{1,2}$, ANIMESH BISWAS ${ }^{1}$, ABU SAYEED MD. ABDULLAH ${ }^{1}$, FAZLUR RAHMAN $^{1}, 3$
}

\begin{abstract}
:
Objective(s): Aim of the study was to use death review to explore medical causes and three delay causal factors responsible for maternal deaths in district or below level health facilities of Bangladesh.

Methods: Government health workers conducted facility based death review in 56 maternal deaths occurred during 2010-2012 in four district and five upazila (EmONC) health facilities of Bangladesh. The data was analyzed to assess the causal relationship between the medical causes and the 'three delays' factors in maternal mortality.

Results: Majority of the mothers died was young (89.3\%; below age 30 years) and died during first pregnancy (78.6\%) and postpartum period (71.4\%). Postpartum hemorrhage and preeclampsia-eclampsia were the foremost causes of maternal deaths at district level facilities of Bangladesh. Seventy two percent of them arrived the hospitals in a travel time $<2$ hour from home or first care-centre when $88 \%$ of cases had an unstable general condition. $72 \%$ of them received treatment within one hour of admission in the hospital. The patients' records reflected that only a few patients received life-saving interventions like blood transfusion, fundal message, and/or oxytocic in postpartum haemorrhage or magnesium sulphate in eclampsia. The study also observed a poor documentation in all the facilities, which was a challenge for death review.

Conclusions: The study suggested improving quality of care and increasing availability of skills to manage the complicated cases in district and below level EmONC hospitals with focused interventions for postpartum haemorrhage and preeclampsia-eclampsia. The 'facility death review' will be useful in identifying causal factors, the third delay factors and service gaps and to respond accordingly to avert similar deaths.
\end{abstract}

Key words: Maternal death, facility, death review, Bangladesh

\section{Introduction:}

Bangladesh has achieved a steady decline in maternal mortality ${ }^{1,2}$. Data showed that the maternal mortality ratio (MMR) has been reduced from 194 to 176 per 100,000 livebirths between 2010 and $2015^{2,3}$ which is still unacceptively high. The improvement is partly due to increasing access to maternal health care including institutional delivery and Emergency Obstetric and Neonatal Care (EmONC) $)^{4,5}$. However, government has been striving to ensure 24/7 EmONC in all facilities with special focus on quality of care initiatives as key strategy to reduce maternal mortality and morbidities ${ }^{4-6}$.

$65.7 \%$ of the population is rural in Bangladesh and the district or below level facilities usually deals obstetric complications from rural areas. A community based death review study has shown that $47.8 \%$ of maternal deaths identified at district and upazila level died in facilities and $17 \%$ died on the way to facility in Bangladesh ${ }^{7}$. The methodology was adapted from the WHO published "Beyond the Numbers 2004" guidelines that include verbal autopsy at community

1. Centre for Injury Prevention and Research, Bangladesh (CIPRB), Dhaka, Bangladesh

2. Department of Obstetrics \& Gynaecology, Kumudini Women's Medical College and Hospital, Mirzapur, Bangladesh

3. Bangladesh University of Health Sciences (BUHS), Dhaka, Bangladesh 
and facility death audit as the important tools to understand preventable medical causes and other factors responsible for maternal deaths ${ }^{8}$. Later in 2013, WHO also published an updated health system model named "Maternal Death Surveillance and Response" (MDSR) that also covers both community and facility level maternal deaths for surveillance, and subsequent death audit that follows response for averting similar death in future ${ }^{9}$. Many a developed and developing countries experienced similar maternal death audit with successes ${ }^{10-16}$.

Bangladesh implemented a "Maternal and Perinatal Death Review" intervention (MPDR) through government health system in four districts namely Takhurgaon, Narail, Moulvibazar and Jamalpur from 2010-2015 7,17 . The MPDR had two important components namely i) community based maternal death review and facility based maternal death audit. Both the audit process used WHO guidelines ${ }^{8}$ and tools adapted locally to identify medical and social causes including health system gaps responsible for those deaths in district or below level government hospitals. A trained group of senior nurses working in maternity ward of the health facilities conducted the maternal death reviews while the consultants or medical doctors supported review process ${ }^{17}$. The implementation experienced a number of successes by demonstrating improved quality of care and reduced maternal deaths ${ }^{17,18}$.

The current study has included data from the death reviews conducted under MPDR in maternal deaths those occurred in district and upazila hospitals during 2010-2012 and analyzed to identify the medical causes and other factors responsible for those maternal deaths.

\section{Materials and Methods:}

The study was conducted in 12 government hospitals located in 4 rural districts of Bangladesh of which four are district hospitals (200-250 bedded) and five are upazila health complexes (UHCs, 50 beds). All these facilities were functioning with EmONC services and receive majority of rural obstetric complications. The Directorate general of health services (DGHS) had implemented the facility death review by the health care providers of those hospitals under MPDR system from 2010 to 2015. UNICEF Bangladesh and CIPRB (Centre for Injury Prevention \& Research, Bangladesh) provided the technical assistance $7,17,18$.
Fifty-six maternal deaths occurred between January 2010 to December 2012 in the selected facilities were studied. One trained senior nurse assigned by hospital authority conducted the death review using a fieldtested "Facility Death Review form" (FDR form) by reviewing hospital records and patient files. The questionnaire was developed to explore the medical causes of the deaths and associated factors related to hospital care using evidence base ${ }^{8}$, pretested and approved by DGHS. The review process ensured due anonymity, confidentiality and non-blaming approach, which is crucial for any death audit ${ }^{8,9}$. The assigned nurse interviewed the relevant health care providers who managed the patient during hospital stay to crosscheck necessary information. The doctors and obstetric consultants helped the nurses in assigning the medical causes of deaths.

The study has also examined 170 verbal autopsies conducted at households of the same districts during 2011-2012 on maternal deaths, who died in hospital to understand any delay in decision-making or transfer to facility for referral of obstetric complications. Trained government health or family planning worker using field-tested questionnaire ${ }^{7}$ conducted the verbal autopsies. The methodological details was also described previously in other articles ${ }^{7,17,18}$.

Analysis of data used a software, SPSS version 23.

\section{Results:}

The table 1 shows important characteristics of the deceased mothers $(n=56)$. The deceased mothers were young with a mean age of $26.4 \pm 4.4$ years and $73.2 \%$ of them were below the age of 30 years. Most of them died during their first pregnancy $(78.6 \%)$ and during postpartum period (71.4\%). Among 56 maternal deaths, 48 women (85\%) died in four District hospitals of which 4 mothers were referred from Upazila health complexes (UHCs) and eight mothers died in five UHCs. The place of death was obstetric ward (85.7\%), labour room $(12.5 \%)$ and only one death in the emergency room of the hospital. Majority (88\%) of them were unstable (general condition) during admission in the hospitals. $42.9 \%$ of them died within 1 hour and another $38.1 \%$ died between 1-7 days of admission. A longer duration of hospital stay (from admission to death) was observed in $19 \%$ of the deaths that ranges from 8 to 33 days. 
Table-I

Characteristics of the mothers died at facility

\begin{tabular}{llc}
\hline & Categories & Number $(\%)$ \\
\hline Age group $(\mathrm{n}=56)$ & $\leq 20 \mathrm{yr}$ & $92(16.1 \%)$ \\
& $21-30 \mathrm{yr}$ & $41(73.2 \%)$ \\
& $\geq 31 \mathrm{yr}$ & $6(10.7 \%)$ \\
Number of index pregnancy $(\mathrm{n}=56)$ & 1 & $44(78.6 \%)$ \\
& $2-3$ & $9(16.1 \%)$ \\
Hospital where died ( $\mathrm{n}=56)$ & $\geq 4$ & $3(5.4 \%)$ \\
& District Hospital $(\mathrm{n}=4)$ & $48(85.7 \%)$ \\
Place of death within the hospital $(\mathrm{n}=56)$ & Upazila Health Complex $(\mathrm{n}=5)$ & $8(14.3 \%)$ \\
& Emergency room & $1(1.8 \%)$ \\
& Obstetric ward & $48(85.7 \%)$ \\
Time of death in relation to pregnancy $(\mathrm{n}=56)$ & Labour room & $7(12.5 \%)$ \\
& Antepartum & $15(26.8 \%)$ \\
& Postpartum & $40(71.4 \%)$ \\
General Condition during admission $(\mathrm{n}=52)$ & Abortion & $1(1.8 \%)$ \\
& Stable & $5(12.0 \%)$ \\
Duration of hospital stay before deaths $(\mathrm{n}=42)$ & Unstable & $37(88.0 \%)$ \\
& $<1 \mathrm{~d}$ & $18(42.9 \%)$ \\
& 1 day -7 day & $16(38.1 \%)$ \\
& $8-14$ day & $4(9.5 \%)$ \\
& $15-33$ day & $4(9.5 \%)$ \\
Mode of delivery $(\mathrm{n}=40)$ & Vaginal delivery & $26(65.0 \%)$ \\
Pregnancy outcome $(\mathrm{n}=40)$ & Caesarean section & $13(32.5 \%)$ \\
& Live births & $29(70.9 \%)$ \\
& Still birth & $11(26.8 \%)$ \\
& Abortion & $1(2.4 \%)$ \\
\hline
\end{tabular}

Of 40 women died postpartum period, 13 deaths (32.5\%) followed caesarean sections and the rest women had vaginal deliveries. $70.9 \%$ of the women died after delivery, had a live birth, $26.8 \%$ had stillbirths; and one case was abortion.

\section{Causes of maternal deaths}

Diagnosis could be determined in 40 maternal deaths from the records, of which $45 \%$ of the deaths occurred due to either antepartum (2 cases) or postpartum haemorrhage ( 16 cases); four cases were with retained placenta. Another $32.5 \%$ of mothers died for severe preeclampsia $(n=6)$ or eclampsia $(n=7)$. The other causes of deaths identified were obstructed labour, puerperal sepsis, heart failure and suspected amniotic fluid embolism (Figure 1). The patients' records also showed that $55.6 \%$ of the mothers died had severe anaemia during admission, $26.9 \%$ had hypertension and $7.7 \%$ had diabetes.' Only one death was due to complications following abortion.

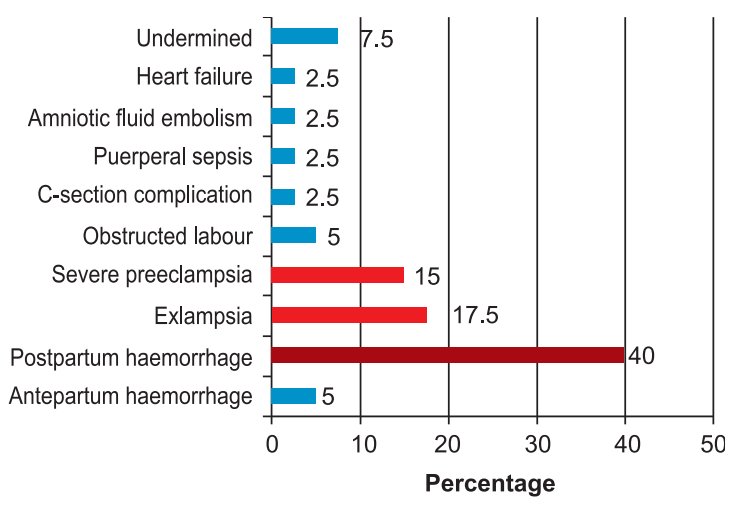

Fig.-1: Distribution of maternal deaths $(n=40)$ by causes of death

\section{Initiation of treatment}

Records shows that the treatment was initiated in $64.3 \%$ of the cases within 15 minutes of admission in the ward or labour room and in $14.2 \%$ of cases by next 15 minutes but delayed over 1 hour in another $21.4 \%$ of cases (Figure 2). Sixty eight percent of the 
cases with hemorrhage and $60 \%$ of cases with preeclampsia-eclampsia received some treatment within 15 minutes while two cases with postpartum haemorrhage and three cases with preeclampsiaeclampsia received treatment after 1 hour of admission.

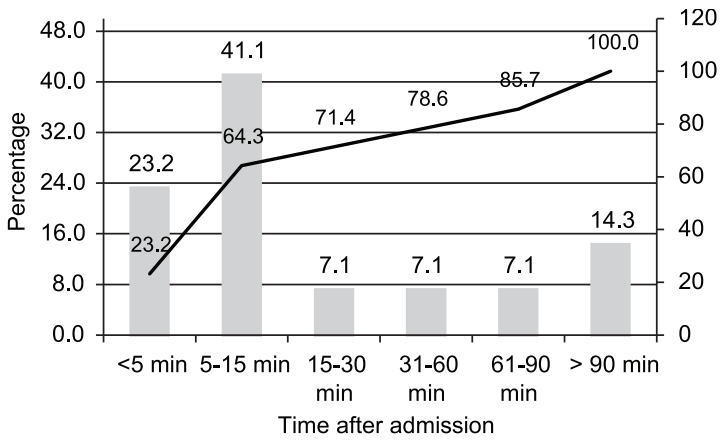

Fig.-2: Delay in initiation of treatment after admission in the hospital $(n=56)$

(Bar: percentage by time group and the line: cumulative percentage)

\section{Care provided in hospital}

The study observed a poor documentation of patient profile and treatment in hospital records, so it was difficult to assess the quality of treatment. According to the records, one case of eclampsia received injection of magnesium sulfate and for management of haemmorrhage, 9 cases $(47.4 \%$ ) received infusion of normal saline, 5 cases (26.3\%) transfusion of blood, 9 cases $(47.4 \%)$ of oxytocic drugs and 5 cases $(26.3 \%)$ received fundal massage. Laboratory tests performed were scarce as per record. $41.1 \%$ of the dead mothers had some records on laboratory tests. Among them, 5 cases had blood grouping and Rh typing, 4 cases had blood tests like complete blood count and blood sugar, one had ultrasonography scan and two had X-ray Chest PA view done.

\section{Referrals}

Information on referral was available in hospital records of 41 deceased mothers. Most $(61 \%)$ of the referrals was made by unskilled persons that include relatives, TBAs or village quacks and rest of referrals by doctors, FWVs, CSBA and medical assistant or equivalents.

For supplementary information on delays that might occur in referral, an additional analysis of verbal autopsies $(n=170)$ was done. The time taken for decision-making for attending facility was less than 1 hour of recognition of complications in $31 \%$ of cases while it delayed over 4 hours from recognition of complications in $41 \%$ cases. However, after decision taken, the majority of them $(72.9 \%)$ could reach hospital by 2 hours of decision taken (Figure 3 ).

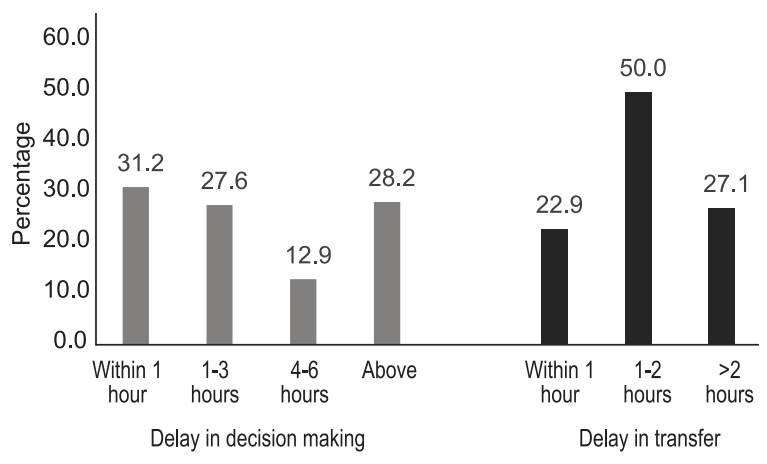

Fig.-3: Delay in decision making and transfer to referral facilities $(n=41)$.

\section{Discussion:}

Bangladesh has successfully implemented a Facility based death review model under a "Maternal and Perinatal Death Review (MPDR)" intervention? ${ }^{7}$. The facility death review covered all maternal deaths occurred in district and upazila (sub-district) level facilities and identified the medical and other causal factors responsible for those deaths. The current study analyzed 56 maternal deaths occurred in 12 rural facilities during 2010-2012.

The women died were young with a mean age of 26.4 year and died in their first pregnancy (78\%). Since the facilities are rural and serves the rural population, the study particularly represents an account on when, where and how mothers dies in rural Bangladesh. The facilities could be reached by less than 2 hours journey when referred from facility or community $(78.6 \%)$. Majority mothers $(72 \%)$ died in obstetric (female) ward and after delivery $(70 \%)$. The cases came late with an unstable general condition on arrival in majority indicating a considerable delay and inappropriate management before referral. Time taken in decisionmaking and transferring to appropriate facility is crucial. District hospitals received and managed the majorities $(85 \%)$ before death, although the upazila hospitals did the same. Most of the referrals were made from community with a few from other lower level facilities. The relatives or unqualified care providers like quacks or TBAs contributed in over half of the referrals that might result in delayed referral and reaching hospital with an unstable general condition ( $88 \%$ cases) when aversion of death became difficult. None of the study 
facilities had an intensive care unit service which was essential to save those dying patients Similar phenomenon was also observed in health facilities in developing countries including Bangladesh who have inadequate capacity to manage obstetric complications $^{19}$.

The current analysis identified haemorrhage (45\%) and preeclampsia-eclampsia $(32.5 \%)$ as the most dominant causes of maternal deaths occurred in district and upazila hospitals. The proportions are higher compare to previous some studies $7,11,18,20$, but represents a speciifc group dealt at peripheral secondary level or EmONC facilities of Bangladesh. The findings deserve attention for immediate actions by enhancing capacity at secondary level facilities of Bangladesh in managing obstetric complications with a focus to haemorrhage and eclampsia. Similar to other studies ${ }^{20-22}$, this study also identified anaemia, obstructed labour, sepsis and abortion as causes in addition to the two major causes for maternal deaths.

Initiation of timely and appropriate management is important in preventing maternal mortality and morbidity. Therefore, any delay in initiating treatment or failure to provide quality of care can affect the outcome. The records showed that most $(71 \%)$ of the cases received some treatment within reasonable time of admission (5-15 min) while $29 \%$ of them took later than half an hour to receive any treatment after admission which is unacceptable. In spite of the treatment, the women could not survive, that obviously raises questions on appropriateness of the care given. This study could not ascertain the appropriateness of the care: whether standard protocols were followed or adequate investigations for management were done because of very poor documentation in patient files. Although evidence based interventions are well known to manage obstetric complications ${ }^{23,24}$; the patient records could not confirm that the dying women had received evidence-based interventions like fundal massage, oxytocic or blood transfusion in postpartum haemorrhage or injection magnesium sulphate in preeclampsia-eclampsia or else. Thus, poor availability of signal functions or standardized care resulted into high maternal mortality at facility: a phenomenon was also observed in other studies ${ }^{25,26}$.

Eighty eight percent of the deceased women, arrived facilities with an unstable general condition, indicating late recognition of complication, delay in decisionmaking and subsequent transfer for referral. The verbal autopsies conducted through same MPDR intervention in maternal deaths found that the decisionmaking for referral was delayed by more than 2 hours in $69.8 \%$ of cases, though the targeted hospitals could be reached in 1 hour of decision made in majority cases $(71 \%)$. The delay could explain presence of other factors ${ }^{7,24,26}$ that influences overall socio-cultural and economic dynamics in referral process which demands contextual and specific studies.

This study also reiterate a success in implementation of health system driven Maternal and perinatal death review (MPDR) for the first time in Bangladesh ${ }^{7,26}$. The facility death review helped implementing remedial actions based on audit data and improved quality of care at facilities $8,11,17,27$. The death review process successfully identified medical causes and health system gaps. The study being focused on secondary level facilities of Bangladesh strongly recommends ensuring skilled care and availability of signal functions for managing priority causes of maternal deaths like bleeding and preeclampsia-eclampsia. The study also observed a strong need for improvement of documentation and continuing the 'facility death review'. Further study using larger sample would be useful to understand the causal factors in preparing responses for accelerated reduction in maternal mortality in rural Bangladesh.

\section{Competing interest: Nothing to declare}

\section{Acknowledgements:}

The authors duly acknowledge the contribution of Directorate General of Health Services and Directorate General of Family Planning including their staffs in the study sites and UNICEF and technical and financial support in implementation of MPDR which the study belong to.

\section{References:}

1. El Arifeen S, Hill K, Ahsan KZ, Jamil K, Nahar $Q$, Streatfield PK. Maternal mortality in Bangladesh: a Countdown to 2015 country case study. Lancet. 2014;384.

2. National Institute of Population Research and Training (NIPORT), MEASURE Evaluation I, B. Bangladesh Maternal Mortality and Health Care Survey 2010. Dhaka, Bangladesh; 2012. 
3. WHO. Trends in maternal mortality: 1990 to 2015: estimates by WHO, UNICEF, UNFPA, World Bank Group and the United Nations Population Division. [cited 2016 Aug 27]. http:// www.who.int/reproductivehealth/publications/ monitoring/maternal-mortality-2015/en/

4. Chowdhury a MR, Bhuiya A, Chowdhury ME, Rasheed S, Hussain Z, Chen LC. The Bangladesh paradox: exceptional health achievement despite economic poverty. Lancet [Internet]. 2013 Nov 23;382(9906):1734-45.

5. DGHS. Health Bulletin 2014.

6. Ministry of Health and Family Welfare Government of the People's Republic of Bangladesh Health, Population and Nutrition Sector Development Program ( HPNSDP ), July 2011 - June 2016.

7. Halim A, Utz B, Biswas A, Rahman F, van den Broek N. Cause of and contributing factors to maternal deaths; a cross-sectional study using verbal autopsy in four districts in Bangladesh. BJOG. 2014 Sep;121 Suppl :86-94.

8. WHO. Beyond the numbers: reviewing maternal deaths and complications to make pregnancy safer. Br Med Bull. 2004;67.

9. World Health Organization. Maternal death surveillance and response: technical guidance, information for action to prevent maternal death. Bull World Heal. 2013; Available from: http:// www.scielosp.org/scielo. php?pid=S004296862011001100003 \&script=sci_arttext \&tlng=pt

10. Pearson $L$, deBernis $L$, Shoo R. Maternal death review in Africa. Int J Gynecol Obstet. 2009;106:89-94.

11. Goswami D, Rathore AM, Batra S, Dubey C, Tyagi S, Wadhwa L. Facility-based review of 296 maternal deaths at a tertiary centre in India: Could they be prevented? J Obstet Gynaecol Res. 2013;39(12):1569-79.

12. Khanam R Ara, Khan M, Halim MA, Begum K, Jahan S. Facility and Community Based Maternal Death Review in Bangladesh. Bangladesh J Obstet Gynaecol. 2009; 24(1): 18-21.
13. Osman H, Campbell OMR, Sinno D, Zarwi R, Nassar AH. Facility-based audit of maternal mortality in Lebanon: a feasibility study. Acta Obstet Gynecol Scand. 2009 Jan ;88(12): 1338-44.

14. Hofman JJ, Mohammed H. Experiences with facility-based maternal death reviews in northern Nigeria. Int J Gynecol Obstet. 2014;126(2): $111-4$.

15. Okonta PI, Okali UK, Otoide VO, Twomey D. Exploring the causes of and risk factors for maternal deaths in a rural Nigerian referral hospital. J Obstet Gynaecol. 2002 Nov;22(6): 626-9.

16. Supratikto G, Wirth ME, Achadi E, Cohen S, Ronsmans C. A district-based audit of the causes and circumstances of maternal deaths in South Kalimantan , Indonesia. Bull World Health Organ. 2002;80 (3): 228-234.

17. Biswas A. Maternal, newborn, child and adolescent health Maternal and Perinatal Death Review (MPDR ): Experiences in Bangladesh. World Health Organisation. 2015 [cited 2016 Jul 19]. p. 1-5. Available from: http://www.who.int/ maternal_child_adolescent/epidemiology/ maternal-death-surveillance/case-studies/ bangladesh-study/en/

18. Biswas A, Rahman F, Eriksson C, Halim A, Dalal K. Facility Death Review of Maternal and Neonatal Deaths in Bangladesh. PLoS One. 2015;10(11):e0141902.

19. WHO, Bangladesh Health System Review. Health system in Transition, Health Systems in Transition Vol. 5 No. 3 2015, [www.wpro.who.int/ asia_pacific_observatory/hits/.../ bgd_health_system_review.pdf]

20. Say L, Chou D, Gemmill A, Tunçalp Ö, Moller AB, Daniels JD et al. Global Causes of Maternal Death: AWHO Systematic Analysis. Lancet Glob Heal. 2014;2(6):e323-33.

21. Khan KS, Daniel Wojdyla, Lale Say, Dr A Metin Gülmezoglu, Paul FA Van Look. WHO analysis of causes of maternal death: a systematic review. Lancet. 2006;367(9516): 1066-74.

22. CDC. Pregnancy-Related Deaths. [cited 2016 Dec 17]. Available from: https://www.cdc.gov/ 
reproductivehealth/maternalinfanthealth/ pregnancy-relatedmortality.htm

23. Darmstadt GL, Bhutta ZA, Cousens S, Adam T, Walker N, de Bernis L. Evidence-based, costeffective interventions: how many newborn babies can we save? Lancet. 2005;365(9463):977-988. doi: 10.1016/S0140-6736(05)71088-6.

24. Campbell OM, Graham WJ. Strategies for reducing maternal mortality: getting on with what works. Lancet. 2006;368(9543):1284-1299. doi: 10.1016/S0140-6736(06)69381-1.

25. Kongnyuy EJ, Mlava G, van den Broek N. FacilityBased Maternal Death Review In Three Districts
In The Central Region of Malawi. An Analysis of Causes and Characteristics of Maternal Deaths. Women's Heal Issues. 2009;19(1):14-20.

26. Pacagnella RC, Cecatti JG, Parpinelli MA, Sousa MH, Haddad SM, Costa ML, et al. Delays in receiving obstetric care and poor maternal outcomes: results from a national multicentre cross-sectional study. BMC Pregnancy Childbirth. 2014;14(1):159.

27. Dikid T, Gupta M, Kaur M, Goel S, Aggarwal AK, Caravotta J. Maternal and perinatal death inquiry and response project implementation review in India. J Obstet Gynaecol India. 2013 Apr;63(2):101-7. 